\title{
Quantifying the contribution of anthropogenic influence to the East Asian winter monsoon in 1960-2012
}

Xin Hao et al.

Correspondence to: Xin Hao (haoxlike91@163.com)

The copyright of individual parts of the supplement might differ from the CC BY 4.0 License. 


\section{Assessment of the atmospheric circulation pattern by model in All-Hist runs}

Taylor diagram (Figure S1) shows the model can well reproduce the climatology of the EAWM-related circulation features in all 15 runs, ensemble average of all runs (referred to as “ensemble_all”) and ensemble average of run1, run2, run5, run13, run14 and run15 (referred to as “ensemble_best”). The surface air temperature, Aleutian low, $500 \mathrm{hPa}$ geopotential height and $300 \mathrm{hPa}$ zonal wind show higher pattern correlations with observations. However, Table S1 shows the correlation between simulation and observation, and the trend coefficient, it suggests ensemble_best can better capture the variability of the EAWM indices and reliably reproduce the long-term trend (one is defined as the area-averaged surface air temperature and the other is defined as the area-averaged $500 \mathrm{hPa}$ geopotential height) than others.

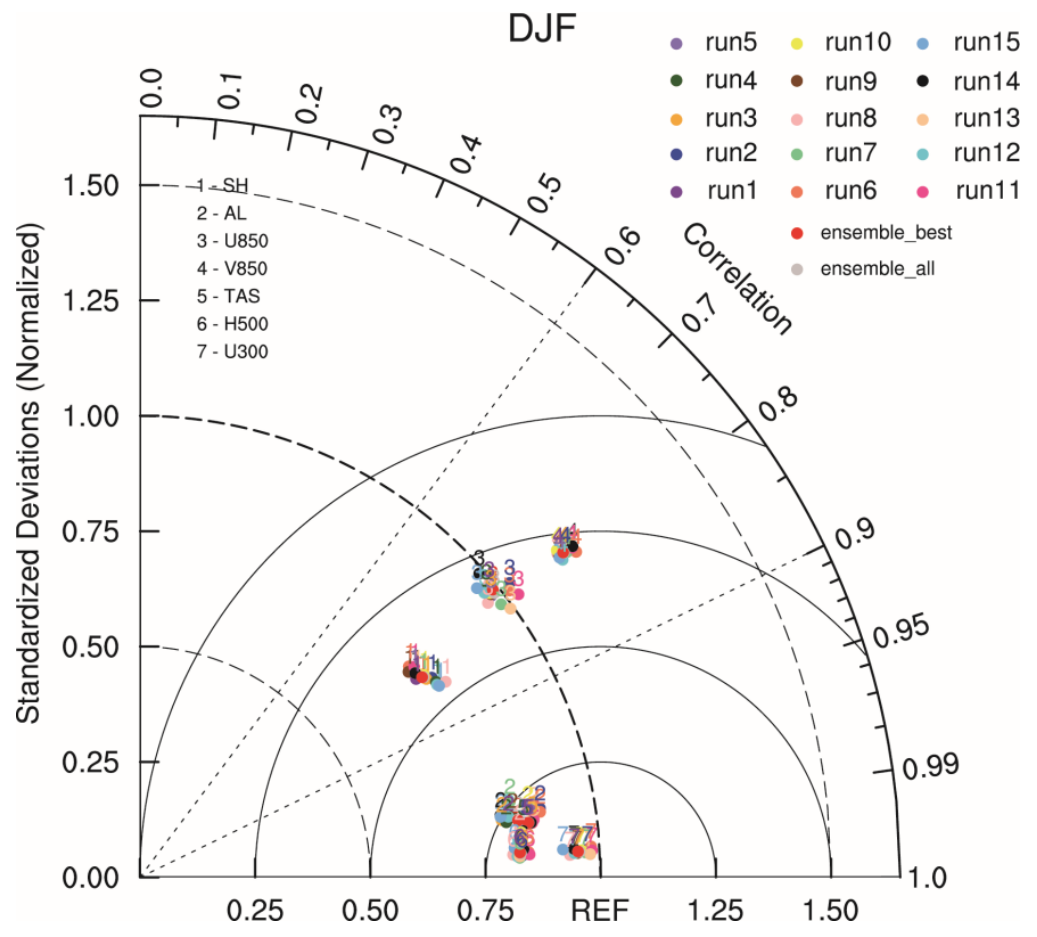

Figure S1 Taylor diagram of winter-mean climatology for Siberian high (SH; $40^{\circ}$ $\left.60^{\circ} \mathrm{N}, 70^{\circ}-120^{\circ} \mathrm{E}\right)$, Aleutian low (AL; $\left.40^{\circ}-70^{\circ} \mathrm{N}, 110^{\circ}-160^{\circ} \mathrm{E}\right), 850 \mathrm{hPa}$ zonal wind (U850; $25^{\circ}-50^{\circ} \mathrm{N}, 115^{\circ}-145^{\circ} \mathrm{E}$ ), $850 \mathrm{hPa}$ meridional wind (V850; $25^{\circ}-$ $\left.50^{\circ} \mathrm{N}, 115^{\circ}-145^{\circ} \mathrm{E}\right), 850 \mathrm{hPa}$ meridional wind (V850; $\left.20^{\circ}-40^{\circ} \mathrm{N}, 100^{\circ}-140^{\circ} \mathrm{E}\right)$, 
surface air temperature (TAS; $25^{\circ}-45^{\circ} \mathrm{N}, 105^{\circ}-145^{\circ} \mathrm{E}$ ), $500 \mathrm{hPa}$ geopotential height (H500; $\left.25^{\circ}-45^{\circ} \mathrm{N}, 105^{\circ}-145^{\circ} \mathrm{E}\right)$ and $300 \mathrm{hPa}$ zonal wind (U300; (27.5 $\left.\left.37.5^{\circ} \mathrm{N}, 110^{\circ}-170^{\circ} \mathrm{E}\right)-\left(50^{\circ}-60^{\circ} \mathrm{N}, 80^{\circ}-140^{\circ} \mathrm{E}\right)\right)$. The area of meteorological variable is selected to define the EAWM index. 
Table S1 "tr" is an abbreviation for "linear trend coefficient” (EAWMI_HGT/EAWMI_SAT). “cor” is an abbreviation for "correlation coefficient between simulated EAWM index under All-Hist scenario and observed EAWM index” (EAWMI_HGT/EAWMI_SAT), "cor_dec" is an abbreviation for "correlation coefficient in decadal time-scale". As a reference, the linear trend coefficient of EAWM_HGT/EAWM_SAT is -0.02/-0.023. The red numbers are significant at the $90 \%$ confidence level.

\begin{tabular}{|c|c|c|c|c|c|c|c|c|}
\hline & run 1 & run 2 & run 3 & run 4 & run 5 & run 6 & run 7 & run 8 \\
\hline Cor & $0.23 / 0.21$ & $0.21 / 0.09$ & $-0.19 /-0.17$ & $0 / 0.16$ & $0.24 / 0.14$ & $0.17 / 0.05$ & $0.08 / 0.22$ & $0.02 / 0.21$ \\
\hline Cor_dec & $0.64 / 0.44$ & $0.63 / 0.81$ & $-0.16 / 0.04$ & $0.64 / 0.52$ & $0.6 / 0.53$ & $0.25 / 0.4$ & $0.3 / 0.78$ & $-0.31 / 0.37$ \\
\hline \multirow[t]{2}{*}{$\operatorname{tr}$} & $-0.032 /-0.016$ & $-0.018 /-0.023$ & $-0.003 /-0.011$ & $-0.016 /-0.012$ & $-0.016 /-0.018$ & $-0.016 /-0.014$ & $0 /-0.017$ & $0 /-0.013$ \\
\hline & run 9 & run 10 & run 11 & run 12 & run 13 & run 14 & run 15 & ensemble_all \\
\hline Cor & $0.1 / 0.05$ & $0.24 / 0.02$ & $0.18 / 0.13$ & $0.027 /-0.055$ & $0.23 / 0.3$ & $0.11 / 0.18$ & $0.07 /-0.06$ & $0.26 / 0.23$ \\
\hline Cor_dec & $0.27 / 0.6$ & $0.57 / 0.38$ & $0.54 / 0.14$ & $0.12 / 0.42$ & $0.67 / 0.63$ & $0.76 / 0.64$ & $0.67 / 0.49$ & $0.67 / 0.57$ \\
\hline \multirow[t]{2}{*}{$\operatorname{tr}$} & $0 /-0.014$ & $-0.011 /-0.015$ & $-0.019 /-0.017$ & $-0.006 /-0.023$ & $-0.02 /-0.018$ & $-0.016 /-0.013$ & $-0.02 /-0.023$ & $-0.03 /-0.04$ \\
\hline & ensemble_best & & & & & & & \\
\hline Cor & $0.31 / 0.3$ & & & & & & & \\
\hline Cor_dec & $0.76 / 0.7$ & & & & & & & \\
\hline $\operatorname{tr}$ & $-0.038 /-0.044$ & & & & & & & \\
\hline
\end{tabular}




\section{Possible reasons for the increase trend in EAWMI in Nat-Hist runs}

Previous studies indicated that the Atlantic multidecadal oscillation (AMO) and Pacific decadal oscillation (PDO) favor a low-frequency variability of the EAWM, and that is the EAWM is weakened (enhanced) during the warm (cold) phase of the AMO/PDO (e.g., Li and Bates 2007; Ding et al., 2014; Hao and He, 2017). As shown in Fig. 2, an obviously increasing in EAWMI during 1960-1980 in Nat-Hist runs. During 1960-1980, both the PDO (downloaded from http://research.jisao.washington.edu/pdo/PDO.latest.txt) and AMO (Trenberth and Shea, 2006) were in a cold phase (Fig. S2), leading an enhanced EAWM. However, the PDO and AMO were out-of-phase after 1980s, causing a combined effect on the EAWM. Thus, we consider that the AMO and PDO may be responsible for the increase trend of EAWMI in Nat-Hist runs. 


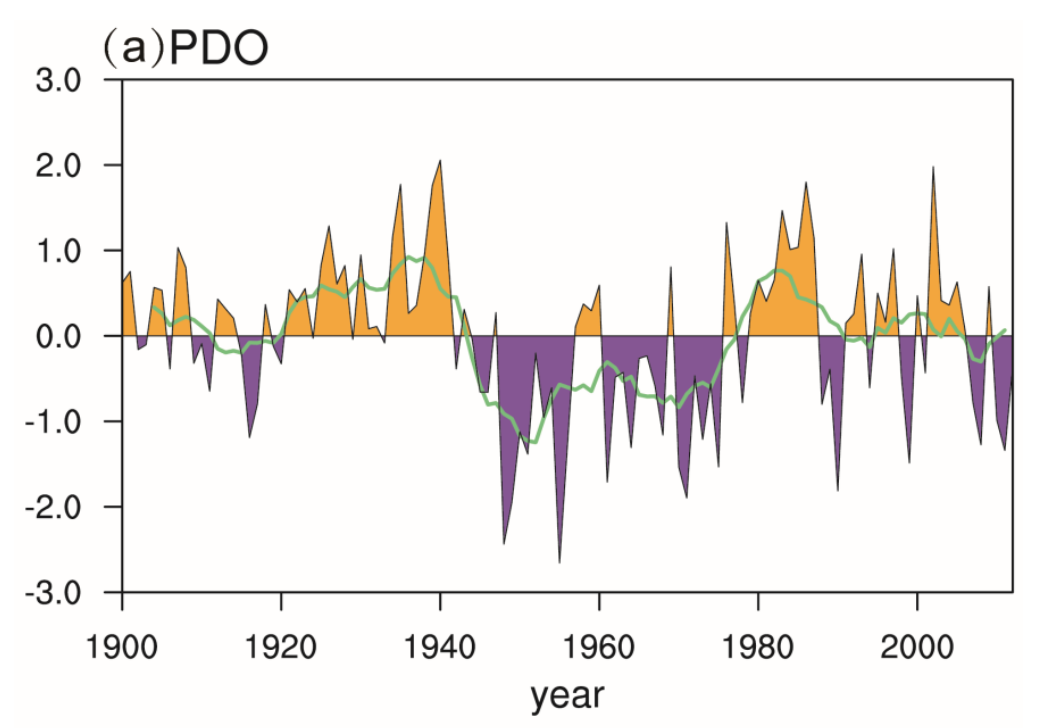

(b) AMO

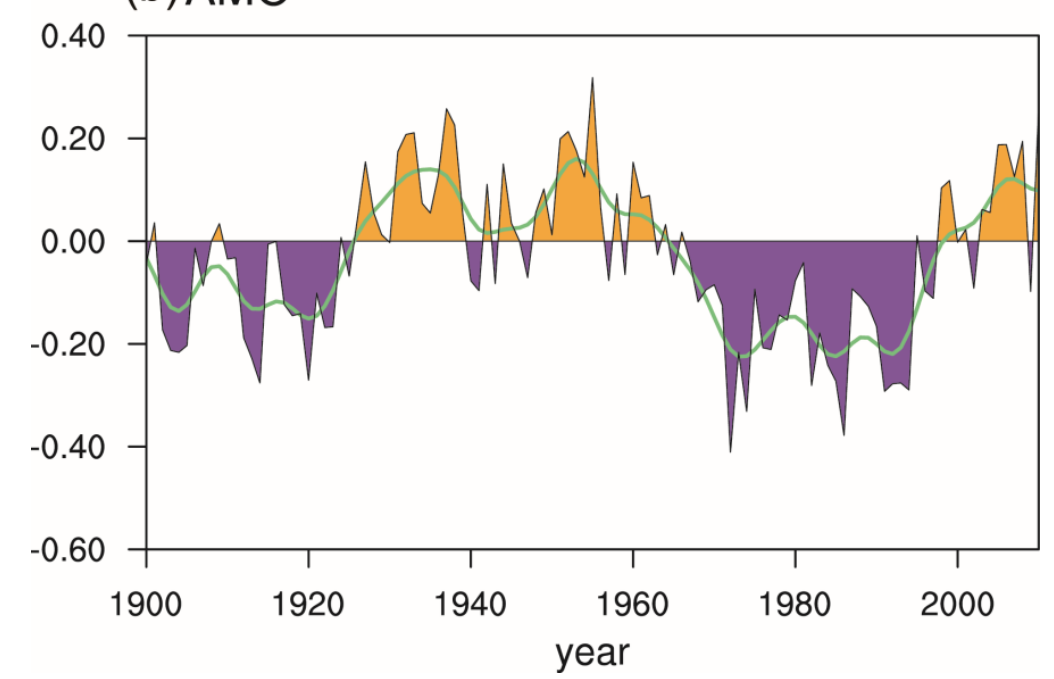

Fig. S2 Time series of the Pacific decadal oscillation (PDO; a) and Atlantic multidecadal oscillation (AMO; b) during 1960-2012. 